\title{
Naciones y Regiones en el Reino Unido*
}

\author{
Colin R. Munro **
}

Sumario: NACIONES Y UNIONES. - DESUNIÓN Y DISCORDIA.- LAS NACIONES EN LA CONSTITUCION ACTUAL.- Sistemas jurídicos. Organización legislativa. Descentralización administrativa.- ¿TIENE REGIONES EL REINO UNIDO?- CONCLUSIÓN.

Como en otros Estados soberanos, especialmente en los grandes o de mucha población, en el Reino Unido también se discute sobre los temas relativos al traspaso $1-0$ descentralización- de las competencias del gobierno central. Una modalidad de transferencia que ha sido absolutamente llamativa desde 1979 -cuando las elecciones generales llevaron al poder a un Gobierno conservador dirigido por la Sra. Tatcher- es la privatización de las que en su día fueron empresas públicas. Sin embargo, la privatización representa simplemente una de las fórmulas por las que los gobiernos de los últimos quince años han buscado para residenciar tanto actividades como funciones administrativas en organismos que son total $o$, al menos parcialmente, independientes del gobierno central 2.

Los autores han hecho notar que este aparente voluntarismo de los últimos gobiernos por transferir competencias $-\mathrm{y}$ responsabilidad-

\footnotetext{
* Traducción: CARLOS GONZÁLEZ ÁLVAREZ, Universidad de León.

* Catedrático de Derecho Constitucional y Decano de la Facultad de Derecho, Universidad de Edimburgo, Reino Unido. Agradezco a mi colega Chris Himsworth sus comentarios sobre el borrador de este artículo, y a Carlos González Alvarez, de la Universidad de León, por su aliento y ayuda.
}

${ }^{1}$ N. del T.: He optado por traducir el difícil término devolution por traspaso o transferencia de competencias, aunque es un concepto en un sentido, más amplio, pues engloba todo cambio de competencias - ya sean legislativas, ejecutivas, administrativas o judiciales-, y, por otro lado, es más estricto, pues la devolution sólo se da en sentido descendente o centrifugo. Su traducción como "devolución" nos podría acercar a la concepción británica del poder originariamente asentado en el pueblo. (ver nota $n^{\circ} 19$ ).

2 De acuerdo con la retórica del partido Conservador, estas reformas habrían tenido el efecto de "hacer retroceder las fronteras del Estado". Sin embargo, dado que en otros muchos aspectos el gobierno central ha expandido su actividad, la realidad resultante es mucho menos nítida en este aspecto. 
por medio de lo que podemos llamar «transferencia vertical" 3 o «desconcentración", no ha ido acompañada por un entusiasmo comparable con respecto a la que podemos llamar "transferencia horizontal» ${ }^{4} \mathrm{o}$ «descentralización" 5 , donde las competencias son transferidas según un criterio geográfico, desde el centro ${ }^{6}$ a las entidades regionales o locales. En este último frente, ha habido escasos progresos en todos estos años desde 19797.

Sin embargo, hasta cierto punto, en el Reino Unido sí se desconcentran geográficamente competencias, y así, la finalidad de este artículo será estudiar y describir las exactas dimensiones de este fenómeno. En particular, se determinará hasta qué punto hay un reconocimiento de las regiones en el ordenamiento constitucional.

Con el término "regiones», me refiero a aquellas áreas geográficas que siendo más pequeñas que el Estado son mayores que el territorio de las Administraciones locales. En el Reino Unido las Administraciones locales son elegidas directamente, las leyes establecen sus competencias y obligaciones - limitadas-, con las que prestar los correspondientes servicios en sus respectivos territorios ${ }^{8}$.

\footnotetext{
${ }^{3}$ N. del T.: El término traducido es «vertical devolution».

4. N. del T.: Traducción de «horizontal devolution».
}

${ }^{5}$ Estos términos se usan con cierta frecuencia, pero desafortunadamente su utilización no es siempre coincidente, así los autores usan el mismo término para referirse a distintos fenómenos.

6 El término "centro" está empleado aquí como una descripción conveniente, a la vez de usual, del lugar donde se asienta el gobierno. En el caso del Reino Unido, este lugar es Londres, donde tiene su sede el Parlamento y la mayor parte del Gobierno estatal. Al contrario que España, pero de forma similar a otros muchos Estados, la sede del gobierno es una ciudad que, geográficamente hablando, no es central.

7 En realidad, por lo que se refiere a las Entidades locales, todos los cambios ocurridos desde 1979 han tendido a hacer decrecer, más que incrementar, su papel y competencias. Ver para una perspectiva general de este tema, MARTIN LOUGHLIN, Local Govermment in the Modern State, 1986; MALCOM GRANT, "Central-Local Relations: The Balance of Power", en J. JOWELL y D. OLIVER (compiladores), The Changing Constitution, $2^{\mathrm{a}}$ edición, 1989.

8 Para Inglaterra y Gales, la norma básica sobre régimen local es la Ley del Gobierno Local de 1972 -modificada posteriormente (una de la reformas fue la abolición en 1984 del Consejo del Gran Londres y de otros consejos de condados metropolitanos)-, que creó un sistema de dos niveles de entidades locales, los condados y los distritos. Para Escocia, la legislación básica es la Ley del Gobierno Local (Escocia) de 1973, también reformada, que también crea dos niveles, regiones (de las que hay nueve) y distritos, excepto 
Mi intención es explorar el territorio que se encuentra entre el nivel estatal y el nivel local en el Reino Unido. Con esta finalidad, el término "región", aunque ha podido servir hasta aquí para indicar la perspectiva del análisis, no es una expresión enteramente adecuada o feliz. El principal asunto a tratar es qué reconocimiento se realiza a nivel constitucional de Escocia, Gales, Irlanda del Norte e Inglaterra. Estos territorios están mejor descritos como "naciones» que como regiones, y de esta premisa vamos a partir en nuestro estudio.

Debe destacarse desde ahora que existen varias semejanzas en esta materia entre el Reino Unido y España. Ambos países están situados en la periferia geográfica de Europa y tienen unas formidables barreras naturales para reforzar su separación. En ambos países se dan movimientos centrífugos basados en reminiscencias de antiguos Estados o en distinciones culturales o religiosas. En los dos, coinciden demandas relativamente fuertes de autonomía total en ciertas partes del territorio junto con demandas muy débiles o inexistentes en otras partes. En ambos Estados, la respuesta a las presiones para una mayor autonomía o un trato especial ha sido eminentemente pragmática, hasta tal punto que se han tolerado diferencias de trato a nivel constitucional. Por otro lado, ni España ni el Reino Unido exhiben un sistema federal puro, aunque los dos muestran algunos caracteres típicamente federales.

Como también ocurre en España, se necesita una buena comprensión de la Historia para descubrir cómo y porqué se ha originado la actual ordenación del Reino Unido. En las dos próximas secciones, esquematizaremos algo de esta historia.

\section{NACIONES Y UNIONES 9}

El Reino Unido, como su nombre sugiere, fue formado por la unión entre las diferentes naciones que coexistían en las Islas Británicas.

Estas naciones eran fusión de los diferentes grupos de nativos y de invasores. Aunque Inglaterra no ha sido invadida con éxito desde 1066,

\footnotetext{
para los tres territorios de las Islas de Orkney, Shetland y Western, que tienen entidades de escalón único o con competencias generales. El Gobierno actual está planeando reformar este sistema favoreciendo la creación de una estructura de nivel único; así se prevé que la futura legislación entre en vigor en los próximos dos años.

9 Vid. COLIN R. MUNRO, Studies in Constitutional Law, 1987, Capítulo 2.; COLIN TURPIN, British Government and the Constitution, $2^{2}$ Edición, 1990, capítulo 4. .
} 
antes de esta fecha lo fue en incontables ocasiones. Los más tempranos habitantes habían sido arrollados por los Celtas en los siglos previos al nacimiento de Cristo. La ocupación romana del territorio correspondiente al que ocupan hoy Inglaterra y Gales comenzó en el año 43 d. C.; y dicha dominación duró hasta el siglo $\mathrm{V}$, cuando empezó a ceder ante las repetidas incursiones de invasores del norte de Europa, entre ellos, los Anglos 10, los Sajones, los Jutos, los Noruegos y los Daneses. Por el siglo IX, los Vikingos daneses dominaban grandes partes del norte y este de Inglaterra, pero el Rey Alfredo, el Grande, los repelió de la zona sur-oeste (Wessex) y sus descendientes y sucesores persistieron en la conquista de los territorios ocupados por los daneses, siempre menos unificados. Cuando el biznieto de Alfredo reinó (959-975), lo hizo sobre un territorio cuyas fronteras no eran muy diferentes de las de la Inglaterra de hoy. Así, desde el siglo X, ha habido solamente un único Rey de Inglaterra; aunque durante otros doscientos años hubo una gran variedad de derechos, con diferentes costumbres locales que prevalecieron en diferentes áreas, incluso tras la conquista normanda en 1066.

El territorio al que nos referimos hoy como Gales nunca existió como una entidad política unificada, a pesar de que algunos caudillos o príncipes llegaron a dominar grandes partes de dicho país. Uno de ellos fue Llewellyn ap Griffith, cuyo título de Príncipe de Gales le fue reconocido por el Rey inglés Enrique II en 1267, pero, tras verse involucrado en una guerra contra el Rey Eduardo I de Inglaterra, primero perdió su territorio y luego su vida, y por virtud del Estatuto de Gales de 1284 11 , esas tierras pasaron a pertenecer al rey de Inglaterra. Esta conquista en el siglo XIII significó el fin de un Estado de Gales independiente que, en realidad, nunca había existido. La zona fronteriza o "Marca Galesa" —que todavía hoy se dice pertenece en parte a Gales-, permaneció bajo el control de unos barones bastante belicosos hasta las leyes de 1536 y 1543, dictadas durante el reinado de Enrique VIII, que establecieron a este respecto su total unión (en completa uniformidad administrativa) con Inglaterra. La política de asimilación fue deliberada y así, en 1746 se promulgó una Ley del Parlamento que explícitamente dispuso que todas las referencias legislativas a "Inglaterra» serían tenidas como hechas a «Inglaterra y Gales» 12.

${ }^{10}$ De cuyo nombre se deriva el de «Inglaterra".

11 N. del T.: Statute of Wales 1284.

12 Es la Ley de Gales y Berwick de 1976. Su contenido fue finalmente derogado por la Ley del Idioma Galés de 1967. 
Escocia había quedado unificada en un solo reino desde comienzos del siglo XI. A pesar de que hubo un breve período de tiempo en el que reconoció la soberanía del Rey Eduardo I de Inglaterra, se reafirmó su independencia tras una guerra exitosa, que culminó en la Batalla de Bannockburn (1314). Desde 1603, cuando el rey escocés Jaime VI sucedió también al trono inglés, los dos países tuvieron el mismo monarca. En 1707, negociaciones llevadas a cabo entre representantes de los Parlamentos inglés y escocés condujeron a un acuerdo de unión, ratificado por sendas leyes de cada Parlamento. Estas Leyes de Unión crearon el Reino Unido de Gran Bretaña 13, instauraron un único Parlamento de Gran Bretaña que sustituyó a los dos Parlamentos existentes y establecieron un sistema sucesorio común al trono. De todas formas, la unión no se diseñó para provocar una completa asimilación. Se incluyeron disposiciones que aseguraran que tanto el sistema judicial como el derecho de Escocia se mantuvieran separados, y para que la Iglesia de Escocia, presbiteriana, continuara siendo la iglesia oficial en la parte norte del Reino, mientras que la Iglesia de Inglaterra, episcopaliana, mantuviera semejante status en el sur ${ }^{14}$.

Dado que Irlanda había sido un reino inferior dentro de la Corona inglesa, que además había sido tratado efectivamente como una colonia, los antecedentes para la posterior unión fueron bastante diferentes. De todas formas, una Ley Británica de 1783 había reconocido la autoridad de un Parlamento irlandés, y en 1800 se permitió a esa cámara legislar conjuntamente con el Parlamento Británico. El nuevo Estado fue el Reino Unido de Gran Bretaña e Irlanda.

\section{DESUNIÓN Y DISCORDIA}

La Leyes de la unión instauraron en Irlanda (que tenía una población mayoritariamente católica romana) la misma iglesia oficial que en Inglaterra, pero ésta fue sólo una de las razones por las cuales la unión, que fue percibida inmediatamente como una forma de perpetuar la do-

13 El nombre de "Bretaña» se deriva del nombre latino de la isla "Britannia». Los nombres de "Gran Bretaña" [Greater Britain o Great Britain] fueron usados para distinguirla de la Bretaña francesa. La primera vez que se usó oficialmente el nombre de Gran Bretaña parece que fue en 1604, cuando el Rey Jaime fue proclamado «Rey de Gran Bretaña».

14 La Iglesia de Inglaterra había sido creada por el Rey Enrique VIII cuando el Papa se negó a anular su primer matrimonio. El Rey celebró el segundo de sus seis matrimonios y rompió con la Iglesia de Roma. Por la «Ley de la Supremacía» en 1534, el monarca se convirtió en la cabeza de la Iglesia de Inglaterra. 
minación inglesa, nunca fue una unión afortunada. La "Liga por el Autogobierno" 15 formada en Irlanda en 1870 recibió fuerte apoyo, y durante los siguientes cincuenta años los problemas de la «cuestión irlandesa» iban a dominar la política interna.

En 1886 y 1893 fueron presentados por el Gobierno dos Proyectos de Ley diseñados para establecer medidas de cierto autogobierno (remedo de independencia) para Irlanda, pero fueron derrotados en una y otra cámara del Parlamento del Reino Unido. Un tercer Proyecto se convirtió en Ley en 1914, pero se impidió que entrara en vigor por causa del estallido de la primera guerra mundial.

Las disposiciones de 1914 recibieron un fuerte rechazo en la esquina noreste de Irlanda, donde la mayoría de la población era protestante y "unionista» (favorecedora de continuar la unión con Gran Bretaña). Tras la primera guerra mundial se intentó otra solución con la Ley del Gobierno de Irlanda de 1920: la partición. La ley previó dos Parlamentos separados y subordinados al de Londres, uno en Belfast - para el territorio equivalente a los seis condados del norte ${ }^{16}-$, y el otro en Dublín —en el sur, para los restantes veintiséis-.

Sin embargo, la Ley de 1920 tampoco tuvo la oportunidad de llegar a tener plena eficacia. En unas elecciones generales, el partido revolucionario independentista, el Sinn Fein, ganó 124 de 128 escaños en los veintiséis condados, y los representantes elegidos no ocuparon sus puestos en Londres sino que formaron una Cámara legislativa (The Dail) y un gobierno provisional para un «Estado Libre Irlandés» en Dublín. El intento del gobierno británico de reprimir este movimiento encontró una gran resistencia en el Ejército Republicano Irlandés, que provocó dos años de auténtica guerra civil. Finalmente, el gobierno británico, cansado del conflicto, transigió en el establecimiento de un Estado Irlandés en 1922. El Tratado permitió que los seis condados del norte pudieran optar, por medio de una votación en su Parlamento subordinado, por salirse de ese Estado y permanecer en el Reino Unido

15 N. del T.: Era la "Home Rule League». La expresión "home rule» significa autogobierno, gobierno en autonomía o "doméstico». Esta expresión tiene como opuesta la de "direct rule», o gobierno directo -se entiende ejercido directamente desde el exterior-. Este gobierno directo se referirá en este trabajo al ejercido por Londres primero sobre Dublín y, luego, sobre el territorio de Irlanda del Norte.

16 La provincia histórica del Ulster había consistido en nueve condados, pero este nombre se usa hoy con frecuencia para designar los seis condados, que forman una provincia absolutamente artificial instaurada con la finalidad de garantizar una segura mayoría unionista. 
bajo las condiciones previstas en la Ley de 1920, cosa que en efecto hicieron. De esta forma, el territorio de «Irlanda del Norte» permaneció siendo parte del reino, que a partir de entonces se convirtió en el «Reino Unido de Gran Bretaña e Irlanda del Norte», mientras que el resto de la isla, al que inicialmente se le dio un status de dominio, gradualmente se fue disociando del Reino Unido, separándose de la Commonwealth para ser finalmente reconocido como una República totalmente independiente.

Paradójicamente, aunque por consecuencia de este proceso, a Irlanda del Norte, que había sido la más obviamente "unionista» de todas las otras partes del Reino Unido, se le dio un Parlamento que no había sido especialmente reclamado, además de disposiciones constitucionales diferentes de aquéllas que se habían obtenido en el resto del Estado.

Gracias a la Ley de 1920, Irlanda de Norte tuvo sus propios poderes legislativo y ejecutivo. El Parlamento estaba compuesto por dos cámaras, una elegida directamente y la otra de forma indirecta ${ }^{17}$. La ratificación real de su legislación la realizaba el Gobernador, que representaba a la Corona. El ejecutivo estaba encabezado por el Primer Ministro y su Gabinete, asistidos por funcionarios. Al Parlamento se le había dado competencia para "dictar leyes para la paz, el orden y el buen gobierno" de Irlanda del Norte. Sin embargo, fueron retenidas como exclusivas del Parlamento del Reino Unido, ciertas materias tales como relaciones exteriores, defensa, nacionalidad y comercio exterior. Incluso, aquella legislación dictada por el Parlamento de Irlanda del Norte que excediese de las competencias tasadas, podía ser declarada nula por los tribunales.

La estructura no era federal, en el sentido normal del término 18 , dado que el Parlamento del Reino Unido (en el que se mantenía una representación de Irlanda del Norte, aunque muy reducida), retenía los poderes supremos y plenarios para legislar sobre Irlanda del Norte. Las competencias del ejecutivo tampoco estaban restringidas. Pero, en la práctica, el Parlamento y el Gobierno de Irlanda del Norte pudieron

17 Su sede fue el Castillo de Stormont, cerca de Belfast, y dicho Parlamento fue conocido como "Stormont", de una forma similar por la que el Parlamento del Reino Unido, radicado en una zona de Londres llamada Westminster, es también conocido a veces como "Westminster» y el Gobierno de Su Majestad es llamado "Whitehall».

18 La definición clásica del federalismo requiere que tanto el gobierno general $\longrightarrow$ central- como los regionales sean cada uno, dentro de su esfera, coordinados e independientes. K.C. WHEARE, Federal Government, $4^{\mathrm{a}}$ edición, 1963. 
disfrutar de un grado sustancial de autonomía en los asuntos internos desde 1922, dado que sus homólogos en Westminster y Whitehall empezaron a mostrarse reacios a intervenir, a menos que se les requiriese.

El sistema de traspaso de competencias -devolution 19- legislativas duró casi quince años, pero en 1968 las quejas de la minoría católica se transformaron en disturbios públicos. Los problemas de terrorismo y las continuas desavenencias fueron empeorando y en 1972 tanto el Parlamento como el Gobierno de Irlanda del Norte cesaron de existir al imponerse de nuevo el gobierno directo de Londres sobre ese territorio.

¿Qué había ido mal? La respuesta se puede encontrar en las circunstancias desfavorables que rodearon el experimento, más que en la descentralización producida. La división existente entre las dos comunidades, un millón de protestantes, abrumadoramente unionistas muy persuasivos, y medio millón de católicos, la mayoría opuestos a la unión, no fue eliminada ni siquiera reducida, sino agravada por la creación de una frontera con el sur. Los problemas de las comunidades se reflejaron en la vida política y así, los partidos políticos en Irlanda del Norte se distinguían principalmente por su actitud ante la unión, lo que hizo que cada elección fuese comparable a un referéndum constitucional. Los partidos unionistas fueron invariablemente los vencedores; y, de esta forma, la minoría católica no sólo no tenía perspectivas de lograr algún poder político a través de las urnas ${ }^{20}$, sino que tenía legítimas quejas de discriminación. Cualquiera de los beneficios que pudo tener la devolution fueron menos obvios para la minoría que algunos de los efectos colaterales no pretendidos.

Desde 1972 ha habido varios intentos de transferir competencias legislativas o ejecutivas a órganos internos de Irlanda del Norte, pero ninguno de ellos ha tenido un éxito perdurable. Uno de los más significantes, en 1974, supuso un intento de restablecer los poderes de una Asamblea y de un Ejecutivo que funcionaran sobre la base de que varios partidos políticos compartieran el poder. Sin embargo, el poder

19 El término "devolution", aunque algo impreciso, se usa habitualmente en el Reino Unido para referirse a aquellas disposiciones que descentralizan funciones de gobierno pero que no suponen renuncia de soberanía ni tampoco llegan a significar ni federalismo ni independencia.

20 En un principio se empleó un sistema de representación proporcional en las elecciones al Parlamento de Irlanda del Norte, pero en 1929 el Gobierno de Irlanda del Norte hizo aprobar unas normas que alteraron dicho sistema electoral. 
duró menos de un año, ya que la violencia del IRA persistió y el descontento de los protestantes culminó en una huelga general que paralizó los servicios esenciales.

La firma del "Acuerdo Anglo-Irlandés» en 1985 fue un síntoma de que las relaciones con el Gobierno de la República de Irlanda habían mejorado, pero los partidos unionistas del Norte lo consideraron como una traición del Gobierno británico y se han opuesto a él. La violencia sectaria continúa en el Ulster, el terrorismo se exporta con frecuencia a la Isla de Gran Bretaña y no se acaba por vislumbrar una solución política ${ }^{21}$.

\section{LAS NACIONES EN LA CONSTITUCIÓN ACTUAL}

Era necesario un vistazo retrospectivo para poder comprender la estructura que tiene hoy el Reino Unido. Pero ya es hora de conjugar el verbo en presente y preguntarnos si, en la Constitución actual, existe reconocimiento de las naciones y hasta qué extremo. Como es bien sabido, el Reino Unido no dispone de Constitución en el sentido habitual del término, ya que no cuenta con un documento especial con el status de derecho superior. No obstante, en un sentido más amplio del término, el Reino Unido sí tiene una Constitución porque obviamente tiene reglas reguladoras del ejercicio y de los límites de los poderes de gobierno.

Si las uniones que crearon el Reino Unido hubieran sido pensadas para producir una asimilación completa, y si tal intento hubiera triunfado, entonces, las identidades de las cuatro naciones constituyentes habrían desaparecido, siendo sustituidas por una identidad británica 22 o del Reino Unido. Este resultado no ha ocurrido. Es más cierto afirmar que la gente de Escocia, por ejemplo, se siente escocesa y también, británica. En Escocia, Irlanda del Norte y Gales han sobrevivido elementos de tradiciones, características y cultura distintivas que han contribuido a crear sentimientos de una identidad nacional separada.

21 Ver BRIGID HADFIELD (Comp.), Northern Ireland: Politics and the Constitution, 1992; C. MCCRUDDEN, "Northern Ireland and the British Constitution", en J. JOWELL y D. Oliver, The Changing Constitution, $2^{\mathrm{a}}$ Edición, 1990.

22 En sentido estricto, Gran Bretaña comprende sólo la isla principal pero no incluye el Norte de Irlanda, que sí es parte del Estado. Sin embargo, el adjetivo "británico" es ampliamente utilizado para calificar la Constitución y el Parlamento, por citar unos ejemplos. 
En Inglaterra, que es más grande y más diversa -y que además puede ser considerada como el socio dominante, en términos políticos-, estos sentimientos son quizás menos obvios.

Esa distintividad persistente de las naciones en el aspecto cultural y otros no habría necesitado verse reflejada en normas constitucionales; pero, de hecho, hay rasgos constitucionales que son diferentes en cada una de las naciones que agrupa el Reino Unido.

Los trataremos bajo tres encabezamientos: Sistemas jurídicos, organización legislativa y descentralización administrativa.

\section{Sistemas jurídicos 23}

Al considerar los poderes legislativos y ejecutivos, la pregunta que nos surge es la siguiente: hasta qué punto las diferencias de trato de las naciones de Escocia, Gales y Irlanda del Norte son tales que nos permite hablar de disposiciones especiales, en adición o en sustitución, de las previsiones para todo el Reino Unido.

Refiriéndonos al tercer poder del Estado, la situación difiere, dado que no hay un sistema jurídico propio del Reino Unido o «británico» 24. Como una consecuencia más de la historia de conquistas y uniones, el Estado del Reino Unido no incluye un solo sistema jurídico, ni tampoco cuatro, sino tres: El derecho inglés, el derecho escocés y el derecho norirlandés.

Antes de la conquista normanda, Inglaterra disponía de una gran variedad de derechos y costumbres locales, pero los instintos normandos favorecedores de una unidad política y de una consolidación administrativa prepararon el camino para el cambio. En el siglo XII, el Rey Enrique II extendió la jurisdicción e incrementó la autoridad de los tri-

$23 \mathrm{~N}$. del T.: Esta es la traducción de Legal systems, expresión que hace referencia sobre todo a la organización de los tribunales, a la actuación de todas las profesiones jurídicas, a las fuentes del derecho y a los distintos procedimientos judiciales. Por ello, hemos creído conveniente traducirlo por "sistemas jurídicos», dado que otras alternativas como «sistemas legales» o «sistemas judiciales», son sólo aspectos parciales de este concepto.

24 No es apropiado hablar de «Derecho Británico» o de «Derecho del Reino Unido» porque no existen dichos sistemas. Sin embargo, estas expresiones se encuentran alguna vez cuando las normas objeto de discusión son comunes a todas las jurisdicciones del Reino Unido. 
NACIONES Y REGIONES EN EL REINO UNIDO

bunales reales y todo ello - junto con el envío de jueces itinerantes por todo el país- significó que en poco tiempo se desarrolló un derecho nativo, llamado "común», a todo el territorio. La jurisprudencia destilada de los distintos casos y el pragmatismo utilizado por los tribunales fueron sacralizados por la doctrina del precedente y, de esta forma, el derecho común permaneció como la más importante fuente del derecho inglés hasta el siglo XX. En el siglo XIII, los Reyes ingleses comenzaron a reunir asambleas, que podemos reconocer como los antecedentes del Parlamento, que llegaría a ser la otra fuente principal del derecho inglés. La supremacía del Parlamento sobre las demás instituciones del Estado fue ampliamente puesta a prueba en los sucesos ocurridos en el siglo XVII, en particular en 1688 cuando se reemplazó a un rey impopular por un rey y una reina más aceptables por el Parlamento de aquél entonces. Los privilegios y autoridad ganados por el Parlamento antes de 1707 no iban a ser rechazados y así siempre se ha considerado que el Parlamento de Gran Bretaña y —después de 1800-, el Parlamento del Reino Unido heredaron tales privilegios.

Como ya hemos visto, el territorio de Gales ha estado sujeto a la Corona de Inglaterra al menos desde el siglo XIII, y se podría discutir si desde fecha anterior. Hubo un intento de promulgar un derecho nativo autorizado para Gales en la época del caudillo Hywel Dda (que murió en el 950), pero Gales en la Edad Media no podía ser considerado en realidad como una unidad política ${ }^{25}$. Parece ser que algo del derecho galés medieval coexistió con el derecho inglés durante algún tiempo después del siglo XIII, pero las Leyes del Parlamento inglés de 1536 y 1543 confirmaron que el derecho inglés iba a ser el aplicado en Gales, aunque por un sistema separado de tribunales. Esta organización judicial separada finalizó en 1830, cuando los circuitos galeses fueron incluidos dentro del sistema de tribunales inglés.

El sistema jurídico escocés suele ser calificado en el derecho comparado como sistema "mixto" ya que tiene cierto parecido con los sistemas de derecho común de Inglaterra y los Estados Unidos pero, y a diferencia de ellos, también exhibe una influencia del derecho civil, derivada de sus conexiones con la Europa continental en los siglos XVI

\footnotetext{
25 Ver DAFYDD JENKINS, The Law of Hywel Dda, 1986; y "Law and Government in Wales Before the Act of Union", en J.A. ANDREWS (comp.), Welsh Studies in Public Law, 1970.

26 Ver M.C. MESTON, W.D.H. SELLAR y Lord COOPER, The Scottish Legal Tradition, 1991; D.M. WALKER, The Scottish Legal System, 6ª Edición, 1992.
} 
y XVII 26. Cuando el Vizconde Stair publicó sus Instituciones en 1681, presentaba el derecho escocés como un sistema coherente de principios labrados a partir de diversas fuentes, principalmente las costumbres nativas, el derecho casuístico, el derecho feudal, el derecho romano y el derecho natural. Este autor fue seguido por otros tales como Erskine, Hume y Bell, quienes son conocidos colectivamente como "Los Escritores Institucionales». Sus trabajos, que tienen el valor de autoridad, forman una tercera fuente del derecho escocés.

El Alto Tribunal de Justicia 27, que data del siglo XII, se convirtió en el principal tribunal de Escocia en materia criminal, y en 1532, el Tribunal de Sesión ${ }^{28}$ fue establecido en Edimburgo como el más alto tribunal civil. El Derecho casuístico se hizo más importante al ritmo en que los tribunales se fueron organizando y las publicaciones de sus decisiones mejoraron. Los actos legislativos ${ }^{29}$ del Parlamento Escocés o de los "Estados» 30 - un Parlamento unicameral en el cual el rey se sentaba junto con los jefes de la Iglesia, lores y burgueses- se hicieron mucho más importantes en el siglo XVII, aunque hay evidencias de que se veían con distinta luz que las Leyes del Parlamento en Inglaterra.

En la legislación promulgada con motivo de la unión en 1707, hubo previsiones para asegurar que el derecho de Escocia permanecería diferenciado y que el sistema de tribunales escocés sería también preservado. En principio, estas intenciones fueron satisfechas. El derecho penal escocés, por ejemplo, tiene, en general, fuentes bastante diversas del inglés, incluso aunque los resultados sean bastante similares; además, el Alto Tribunal de Justicia, en funciones de apelación, es el órgano judicial supremo en materia criminal. En asuntos civiles, desde 1707, la Cámara de los Lores es el tribunal supremo de apelación ${ }^{31}$. Por esta razón y por causa de tener un órgano legislativo común, la similitud entre el derecho escocés y el derecho inglés ha tendido gradual-

27 N. del T.: Traducción que hago del "High Court of Justiciary».

28 N. del T.: "Court of Session".

29 N. del T.: Traduzco «enactments" por "actos legislativos" ya que tiene una significación más amplia que las meras leyes.

${ }^{30}$ N. del T.: En inglés, «Estates».

31 La Cámara de los Lores - técnicamente, una comisión de este órgano legislativo- tiene su sede en Londres. Normalmente, dos de los jueces designados para formar sala están cualificados en derecho escocés. El tribunal se constituye como tribunal de apelación para el derecho escocés, inglés o norirlandés, según el caso a decidir. 
NACIONES Y REGIONES EN EL REINO UNIDO

mente a incrementarse, aunque dichos sistemas permanezcan analíticamente diferenciados.

El sistema jurídico norirlandés está menos diferenciado que el escocés, pero de todas formas, debe considerarse como un sistema separado ${ }^{32}$. Antes de la llegada de los normandos, Irlanda estaba regida por el derecho Brehon, un sistema basado en costumbres tradicionales según eran formuladas por unos juristas nativos muy respetados que recibían el nombre de "Brehons". Desde el siglo XII hasta comienzos del XVII, el derecho común inglés era aplicado en las partes de Irlanda que estaban bajo control inglés, aunque existía un regreso al derecho brehon en aquellos lugares y momentos a los que no alcanzaba dicha dominación inglesa La reconquista de Irlanda por los Tudores puso todo el territorio irlandés bajo el control inglés, y a partir del Caso de Tanistry (1607), se afirmó que el derecho brehon ya no formaba parte del derecho de Irlanda.

Es desde el siglo XVII, por tanto, cuando el derecho común inglés conforma los fundamentos del derecho irlandés. Las diferencias que podían aflorar eran debidas a la organización constitucional. Así, el derecho vigente en Irlanda pudo ser reformado por el Parlamento irlandés durante el siglo XVIII, y la subsiguiente unión permitió al Parlamento del Reino Unido promulgar legislación diferente -o dictar la inaplicación de ciertas leyes - para Irlanda. Por estas razones, existen diferencias en el derecho inmobiliario, matrimonial y de divorcio, y en otras pocas materias, aunque la mayor parte de los contenidos del derecho inglés y del irlandés eran idénticos.

Después de 1920, el derecho de la parte de la isla que a nosotros nos interesa, Irlanda del Norte, pudo ser modificado por actos legislativos del Parlamento de Irlanda del Norte - hasta su disolución-, aunque en muchos aspectos la práctica fue seguir la legislación británica. La reimposición del gobierno directo desde Londres ha tendido, sobre la mayoría de los campos del derecho, a ampliar la asimilación del derecho inglés, aunque en algunas áreas del derecho público - tales como el derecho de emergencia y seguridad y el derecho antidiscriminatorio-, la peculiar situación de Irlanda del Norte ha provocado diferencias. El ser miembro de la Comunidad Europea ha conducido, por supuesto, a la armonización de los derechos de los tres sistemas del Reino Unido como lo ha hecho también en el resto de los Estados miembros, en todas aquellas áreas de competencia comunitaria.

32 Ver BRICE DICKSON, The Legal System of Northern Ireland, $2^{\mathrm{a}}$ Edición, 1989. 


\section{Organización legislativa}

Dado que existen tres sistemas jurídicos, es natural que nos detengamos a considerar hasta qué punto existen sus correspondientes órganos legislativos. De igual forma, al no haber un sistema jurídico galés, no existe legislación para Gales sino para Inglaterra y Gales, y así, no podremos esperar encontrar variaciones en los procedimientos parlamentarios que tengan en cuenta el hecho distintivo de Gales ${ }^{33}$.

En realidad, ninguno de los tres sistemàs jurídicos tiene una legislatura con la finalidad de dictar normas para cada uno. El Parlamento de Irlanda del Norte, durante el tiempo que duró, podría haber sido catalogado de esta forma, pero como ya hemos visto, fue un órgano legislativo subordinado.

Ni Inglaterra ni Gales ni Escocia tienen su propio órgano legislativo desde 1707. Los legislativos separados fueron reemplazados por un Parlamento Británico común que, por el ya aludido suceso de 1800, fue sustituido por el «Parlamento del Reino Unido de Gran Bretaña e Irlanda».

La soberanía o supremacía del Parlamento del Reino Unido, comentados por el escritor - ya clásico- Dicey en el siglo XIX, representa uno de los más destacados principios de la Constitución británica. Dicey declaró que «no hay persona o cuerpo de personas que puedan dictar normas que puedan prevalecer o derogar una Ley del Parlamento, o que puedan ser aplicadas por los tribunales en contradicción con una Ley del Parlamento" 34. Por medio de esta proposición, él estaba demostrando la ausencia de poderes legislativos que pudieran competir con el Parlamento, dado que bastante antes del siglo XIX, la competencia de la Corona para legislar había sido restringida y el derecho de origen jurisprudencial era considerado subordinado. En el siglo XIX, no existía otro legislativo, excepto hasta donde llegaban los limitados poderes para legislar que habían sido delegados por el Parlamento a ciertos entes tales como las Administraciones locales 35 .

\footnotetext{
33 Puede haber ocasionalmente legislación que es sólo (o casi sólo) relevante para el territorio de Gales, como es el caso de la Ley del Idioma Galés de 1967. Sin embargo, tales leyes forman parte del derecho de Inglaterra y Gales (o, como normalmente es nombrado, del derecho inglés).
}

34 A.V. DICEY, Introduction to the Study of the Law of Constitution, 10, pág. 40.

35 La doctrina del derecho comunitario de primacía de su derecho sobre las disposiciones legales nacionales supone obviamente un reto o amenaza a la supremacía del Parla- 
El Parlamento del Reino Unido, hoy en día, como en tiempo de Dicey, puede aprobar la legislación que quiera. Así, puede legislar para el Reino Unido en su totalidad, o sólo con aplicación en Escocia o sólo en Irlanda del Norte o sólo en Inglaterra y Gales, o en cualquiera de las combinaciones posibles de estas alternativas ${ }^{36}$. Además, dentro de una ley puede haber una diversa aplicación o «extensión» - según el término tradicional- de sus distintas partes.

Existen expectativas borrosas en Escocia y en Irlanda del Norte - derivadas de ciertas disposiciones de la legislación de la unión o de diferentes tradiciones jurídicas o de otro tipo-, sobre cómo debería legislar el Parlamento sobre dichas materias; pero, dichas expectativas escocesas o irlandesas son frustradas con bastante frecuencia. Esta tendencia a la "Anglocentricidad" se podría explicar, que no excusar, por el hecho de que hay 562 miembros de la Cámara de los Comunes que representan distritos electorales de Inglaterra y Gales, de un total de 651 37. Un vistazo al Boletín Oficial 38 podría sugerir que existe tal tendencia. Sus síntomas, por lo que corresponde a Escocia, podrían ser vistos tanto en la falta de encontrar el suficiente tiempo parlamentario para una legislación diferenciada como en la ocasional insensibilidad a las diferentes

mento. Sin embargo, los tribunales ingleses han distinguido entre contradicción surgida por accidente o descuido (en cuyo caso se dará prioridad al derecho comunitario porque tal previsión ha sido la voluntad del Parlamento manifestada en la Ley Preparatoria [paving act], la Ley de la Comunidad Europea de 1972), por un lado, y contravenciones deliberadas, por la otra (cuando parece que la Ley del Parlamento le habría dado eficacia). Ver Macarthys Ltd v. Smith [1979] 3 All ER 325, Garland v. British Rail Engineering Ltd. [1979] 2 AC 751.

\footnotetext{
36 Como asunto de interés, podemos apuntar que en un recuento de las Leyes del Parlamento aprobadas en el año natural de 1992 se puede apreciar que, de un total de 61, 30 eran aplicables al Reino Unido en su conjunto, 3 exclusivamente a Irlanda del Norte, 2 a Escocia, 10 a Inglaterra y Gales, y 16 a Gran Bretaña (esto es, Escocia, Inglaterra y Gales). En este cómputo estoy ignorando la llamada «legislación privada» (Leyes aprobadas por el Parlamento, por un procedimiento diferente, que no altera el derecho general del territorio, sino que es de aplicación a unas personas en concreto o a unas localidades en particular).
}

${ }^{37}$ Los distritos electorales en el Reino Unido son sólo aproximadamente iguales en número de electores. La ley de Distritos Parlamentarios de 1986 permite la aplicación de otros factores para su determinación, tales como consideraciones geográficas o respetar los límites de los distintos entes locales. Escocia, con 72 distritos, está tratada más generosamente que si se utilizara una estricta igualdad aritmética (perdería unos 13 representantes). A Gales sucede algo similar.

38 N. del T.: Nos.referimos al llamado "Statute Book", que es un corpus que recoge las leyes en vigencia. 
tradiciones jurídicas, siempre que el derecho sea el reformado por una Ley que se aplica a toda Gran Bretaña o a todo el Reino Unido.

Se pueden hacer algunas variaciones mínimas en los procedimientos parlamentarios usuales para aprobar proyectos de ley (o partes de esos proyectos) que sean de aplicación exclusiva en Escocia. Las reglas de procedimiento de la Cámara de los Comunes permiten que tales propuestas sean debatidas por la Gran Comisión Escocesa ${ }^{39}$ (un órgano compuesto por todos los 72 diputados escoceses) en la fase de Segunda Lectura ${ }^{40}$, que es la mejor oportunidad para debatir los principios del proyecto, en lugar de hacerlo en el pleno de la Cámara ${ }^{41}$. Una vez realizada la fase de comisión de estos proyectos (que es la ocasión para debatir las materias en detalle) puede ser remitida a la Comisión Permanente Escocesa 42, compuesta por unos dieciséis o veinte diputados. Otra reforma en 1980 permitió a la Gran Comisión Escocesa reunirse en Escocia. Estos son, quizás, pequeños gestos simbólicos, pero incluso los gestos simbólicos reflejan algún reconocimiento de nacionalidad ${ }^{43}$.

\begin{abstract}
${ }^{39}$ N. del T.: «Scottish Grand Committee».
40 N. del T.: Esta es una de las fases del procedimiento de aprobación de las leyes en el Parlamento, que en apretadísimo resumen es el siguiente. Cada Proyecto de Ley debe ser presentado por un ministro en los Comunes, o Cámara Baja. Recibe una primera lectura, fase absolutamente formal, dado que en realidad sólo se lee el título y se ordena su impresión. También se fija un día para la segunda lectura. Junto con el texto del proyecto se imprime un Memorándum Explicatorio, que aclara en términos no técnicos su contenido y objeto. Si implica aumento del gasto público se añade otro Memorándum Financiero. En la fase de la segunda lectura se discuten los principios del Proyecto por el Pleno de la Cámara -aunque existan ciertas excepciones, como la que hemos visto-. Después de recibir esta segunda lectura se pasa a la fase de comisión, donde ya se analiza el proyecto artículo por artículo y las correspondientes enmiendas. Seguidamente, la Cámara en Pleno vuelve a debatir sobre el proyecto en la fase de informe, procediendo una tercera lectura, antes de pasar a la Cámara de los Lores, donde se repiten las fases, con ligeras diferencias. Si el proyecto es aprobado por ambas Cámaras se presenta a la ratificación real [royal assent].
\end{abstract}

41 Es muy raro que se apruebe legislación exclusiva para Gales, pero -en ese casopuede ser remitida a la Gran Comisión Galesa (compuesta por todos los Miembros del Parlamento MP's de Gales y hasta otros cinco) para la Segunda Lectura. La misma Comisión también puede debatir sobre asuntos galeses. No hay Comisión Permanente Galesa.

42 N. del T.: «Scottish Standing Committee».

43 En marzo de 1993, el Gobierno publicó unas propuestas para ampliar el papel de la Gran Comisión Escocesa, que podría reunirse más frecuentemente y tener sesiones de pregunta - [question time]-, como también debates. También se proponen otras reformas menores. Vid. Scotland in the Union: a partnership for Good (Cm 2225). 
Por lo que se refiere a Irlanda del Norte, el problema es algo diferente. Con la reasunción del gobierno directo por Londres, se introdujo un procedimiento que permite al Secretario de Estado para Irlanda del Norte legislar por medio de Ordenes del Consejo - una forma de legislación subordinada 44_- 45 , y éste se ha convertido en el sistema más normal de legislar. Tales Ordenes del Consejo están normalmente sujetas a la aprobación $\multimap$, alternativamente, a la ausencia de desaprobación- de las dos cámaras del Parlamento, pero en la práctica las oportunidades para debatir o modificar esas propuestas son muy limitadas sino inexistentes. Podemos concluir sin temor a equivocarnos que los mecanismos habilitados para promover y debatir la legislación de Irlanda del Norte son insatisfactorios ${ }^{46}$. Aquí podemos ver una diferencia de trato de Irlanda del Norte, como también podemos recordar que las diferencias no significan invariablemente mejor trato.

\section{Descentralización administrativa}

Un tipo de descentralización en la esfera ejecutiva del gobierno podría significar la presencia de asambleas regionales directamente elegidas, con responsabilidad para diseñar las políticas regionales y administrar los asuntos regionales dentro del marco de las leyes y políticas determinadas centralmente. No existe descentralización de las funciones de gobierno de este tipo en el Reino Unido.

Sin embargo, el Reino Unido sí muestra ejemplos de lo que puede denominarse descentralización administrativa, por medio de la cual, el

\footnotetext{
44 N. del T.: "Legislación subordinada» es aquella legislación de rango inferior a las leyes del Parlamento. Hay que percatarse de la diferente naturalezá de las fuentes escritas del derecho británico, dado que no existe una absoluta correspondencia con nuestros arquetipos. Cabría traducir esta expresión como reglamentos dictados por delegación del Parlamento; asi, existen competencias normativas delegadas por el Parlamento a numerosos entes públicos, tales como la Corona, ministros, administraciones locales e, incluso, empresas públicas [public corporations]. Las normas que, así habilitados, emanen estos órganos, y que pueden tomar numerosas formas (Orders in Council, Proclamations, Royal Warrants, Regulations, Rules, Orders, Schemes y Warrants, entre otras), son consideradas como legislación subordinada, aunque tendrán la irresistibilidad de las verdaderas leyes frente a los Tribunales.
}

45 La Ley para Irlanda del Norte de 1974, sección 1.3 y Anexo 1. Muchas Leyes del Parlamento también permiten que por medio de legislación subordinada se reforme el derecho de Irlanda del Norte.

46 Ver C. PALLEY, "Constitutional Solutions to the Irish Problem", en Current Legal Problems, 1980, p. 121; BRIGID HADFIELD, The Constitution of Northern Ireland, 1989. 
gobierno central, sin crear asambleas ni gobiernos regionales, establece qué aspectos de su cometido puedan ser llevados a cabo por un departamento que esté definido territorialmente y no funcionalmente. Sí ha habido este tipo de descentralización administrativa hacia Escocia y Gales y, desde el año 1972, para Irlanda del Norte ${ }^{47}$.

Después de la unión de 1707 , no había razones para que se tuvieran que hacer previsiones especiales para Escocia en materia de competencias de gobierno. Sin embargo, en 1889, justo cuando la cuestión irlandesa del autogobierno se había convertido en urgente, se decidió diferenciar más claramente la llevanza de los asuntos escoceses. Así, se creó una "Oficina Escocesa», como un departamento del Gobierno, cuyo ministro, el Secretario para Escocia, era responsable del derecho y orden, educación y otras pocas materias. Desde 1892, comenzó la práctica de destinar un puesto dentro del Gabinete al ministro, y en 1926 su cargo fue elevado al rango de Secretario de Estado ${ }^{48}$. Desde 1939, la sede principal de la Oficina Escocesa está en Edimburgo.

Con el paso de los años, las funciones y la importancia de la Oficina Escocesa han sido gradualmente incrementadas. Hoy, el Secretario de Estado, con cuatro ministros junior y una Oficina Escocesa organizada en cinco subdepartamentos, es competente en agricultura y pesca, artes, granjas, educación, medio ambiente, el servicio de bomberos, bosques, salud, vivienda, asistencia a la industria, algunas materias judiciales, administración local, policía, prisiones, carreteras, desarrollo

47 Ver A.G. DONALDSON, "Administrative and Legislative Devolution», en JOHN P. GRANT (comp.), Independence and Devolution: The Legal Implications for Scotland, 1976.

48 N. del T.: La composición del Gobierno del Reino Unido es de relativa complejidad, derivada de la pervivencia de ciertas costumbres. Es el Primer Ministro el que elige a sus "Ministros», que pueden tener distinto rango. Cada Departamento de Estado está dirigido por un "Ministro" o por un "Secretario de Estado" (la distinción entre ambos títulos es más bien histórica, y aunque perciben el mismo salario, los Secretarios de Estado suelen estar al cargo de los departamentos más importantes). Cada ministro cabeza de departamento está asistido por uno o varios "Ministros junior", que pueden ostentar el título de Parlamentary Secretaries, Parlamentary Under Secretaries o Ministers of State. La tendencia actual es la concentración de funciones y cargos, lo que conlleva a la creación de "super departamentos».

Hay que tener en cuenta que «Gobierno y «Gabinete» [Cabinet], no son términos sinónimos. El Gobierno engloba a todos los ministros de los distintos rangos antes mencionados, mientras que el Gabinete es un comité del Gobierno, consistente en unos veinte miembros principales del mismo que se reúnen con el Primer Ministro para supervisar y coordinar el trabajo de todo el Gobierno. 
rural y urbano ${ }^{49}$, trabajo social, deporte, transporte, turismo y planificación urbanística, así como otros departamentos menores y empresas públicas -siempre que operen en Escocia-. En alguna otra materia, el ministro para asuntos escoceses es competente conjuntamente con el ministro con competencias generales -distribución funcional, no territorial一, y normalmente actúa como portavoz de los intereses y opiniones de Escocia dentro del Gabinete y en otros sitios.

Escocia probablemente ha mejorado con el sistema de Secretario de Estado. La administración ha sido mejor por la razón de que el funcionariado de la Oficina Escocesa ha estado siempre más próximo a las preocupaciones del país y de su gente. La políticas pueden ser formuladas y modificadas más ajustadamente. Por otro lado, ha habido un gasto per capita más alto que en Inglaterra y Gales, aunque hay otras razones, como las peores comunicaciones, que pueden justificar dicha diferencia 50 .

De cualquier forma, el mismo sistema ha sido aplicado, aunque con una evolución algo más lenta, a Gales. En 1951 se creó el cargo de Ministro para Asuntos Galeses, pero el establecimiento de un departamento independiente con su propio Secretario de Estado solamente data de 1964. La Oficina Galesa ha recibido competencias adicionales de tiempo en tiempo, desde su instauración, pero tienen menos extensión que las de su homóloga escocesa, así, por ejemplo, no se comprenden competencias sobre policías, prisiones o asuntos judiciales, por citar algunos ejemplos. Sin embargo, como dijimos para Escocia, la implantación del sistema del Secretario de Estado ha sido beneficiosa para Gales.

Bajo circunstancias relativamente diferentes, desde 1974, con motivo de la imposición del gobierno directo desde Londres ha habido Secretario de Estado para Irlanda del Norte. Este ministro podía ser visto como un reemplazo de los gobiernos elegibles diseñados por los Parlamentos de Irlanda del Norte. Este Secretario de Estado ostenta competencias sustanciales, que ejerce con tres o cuatro ministros $j u$ nior y seis sub-departamentos (Agricultura, Desarrollo Económico, Educación, Medio Ambiente, Finanzas y Personal y Salud y Servicios

\footnotetext{
49 N. de T.: Recordemos que la concepción del urbanismo es ligeramente distinta en el Reino Unido que en nuestro país. "Rural and urban development" coincidiría más con la ordenación del territorio y su desarrollo integral, que con las estrictas labores urbanísticas, más aun cuando existe el "town planning".

50 Escocia, Gales e Irlanda del Norte parecen tener trato preferente en el gasto público, pero las comparaciones son difíciles. Hay que tener en cuenta que algunas de las partidas presupuestarias se distribuyen exclusivamente según criterios fijos, según fórmulas.
} 
Sociales). También tiene funciones especiales según el derecho regulador de los estados de excepción, competencias sobre el sistema penal y la tarea de dictar normas en casos de necesidad.

Una debilidad que tiene el sistema de Secretaría de Estado en su propio núcleo es que los poderes administrativos no están apropiadamente contrapesados con una respectiva legitimación política. Los tres Secretarios de Estado mencionados son ministros del gobierno del Reino Unido, y no son responsables ante Asambleas elegidas en sus respectivos territorios, así que tienen algo de la apariencia de gobernadores coloniales. Algunas veces, ni siquiera son representantes parlamentarios de un distrito radicado en el territorio en cuestión 51. Con bastante frecuencia, el Secretario de Estado mantiene una política divergente de la defendida por la mayoría de los diputados de dicho territorio, ya que la representación política de dicho territorio puede diferir de las mayorías que existen en la Cámara Baja, en su conjunto 52. Hay problemas para exigir responsabilidades, así como de legitimación. Los procedimientos y el calendario del Parlamento del Reino Unido no dan la suficiente oportunidad para el control de las actividades de esos grandes departamentos gubernamentales 53 .

Examinado detenidamente, el sistema de los Secretarios de Estado se vislumbra, a pesar de que generalmente no se reconozca así, como un torpe compromiso. Sin embargo, tiene algunos méritos; Escocia y Gales, en reconocimiento a su nacionalidad, reciben especial consideración, que, al menos, puede ser suficiente para aplacar las demandas más templadas de trato diferenciado. Por lo que se refiere a Irlanda del Norte, la descentralización administrativa es vista como una medida coyuntural para salir del paso, mientras los gobier-

\footnotetext{
51 Algunos de los secretarios de Estado para Gales de los años recientes (tales como Peter Walker y el actual ministro, John Redwood), eran ingleses que representaban distritos de Inglaterra. Los Secretarios de Estado para Irlanda del Norte desde 1974 han sido miembros de gobiernos conservadores o laboristas, cuyos partidos no ostentan ningún distrito electoral en Irlanda del Norte (que son habitualmente ganados por los partidos norirlandeses, que no participan en las elecciones de la isla principal).
}

52 El Partido Laborista ha ganado la mayoría de los escaños de Gales en todas las elecciones generales desde 1935, y la mayoría de los escaños en Escocia en todas las elecciones generales desde 1959. Sin embargo, los Conservadores han estado en el Gobierno de un total de 48 años- unos 31 años, a contar desde 1945.

53 La creación, en 1979, de unas Comisiones Especiales de la Cámara de los Comunes que directamente examinaban el trabajo de los distintos departamentos gubernamentales fue una útil reforma, pero los problemas persisten. 
NACIONES Y REGIONES EN EL REINO UNIDO

nos continúan devanándose los sesos para decidir qué es lo próximo que deben hacer.

\section{¿TIENE REGIONES EL REINO UNIDO?}

Recordemos que la intención de este trabajo era examinar la presencia $\longrightarrow$ ausencia - de niveles intermedios de gobierno, que no fueran ni estatales ni locales, sino regionales.

Sin embargo, hemos estado tratando sistemas nacionales y sus diferencias. Podemos preguntarnos porqué ha sido preferible referirnos a Escocia, Gales e Inglaterra como naciones y a Irlanda del Norte como el resto de otra nación.

Francamente, no puede haber una prueba simple y objetiva para distinguir lo que es nación de lo que es región ${ }^{54}$. El haber sido Estado en el pasado puede ser un factor favorecedor pero, para que Gales deba ser considerada como una nación, dicho factor no puede ser decisivo. Otros factores como un idioma diferente (incluso si es minoritario) y una cultura distintiva pueden ser también relevantes. El hecho de que se perciba dicha identidad, tanto interna como externamente, es también un elemento importante; como es cierto que muchos escoceses y galeses, orgullosos de sus orígenes, podrían ofenderse si sus países son calificados de regiones. Debemos percatarnos, por supuesto, que en estas preguntas subyacen implicaciones políticas. Las reclamaciones nacionalistas son más exigentes que las demandas regionalistas.

El tamaño puede ser también importante en esta materia. El término región puede ser bastante apropiado para territorios de la superficie -y población- de Gales 55 o de Irlanda del Norte ${ }^{56}$, si se ignoran otros factores. Sin embargo, nuestro concepto usual de región

\footnotetext{
54 Ver D. MARQUAND, "Nations, Regiones and Europe», en BERNARD CRICK (comp.), National Identities, 1991.

55 La superficie de Gales es de unos $20.750 \mathrm{~km}^{2}$ (lo que hace alrededor de una doceava parte del tamaño del Reino Unido). Su población, unos 2.857 .000 habitantes, es un 5 por ciento de la total del Reino Unido.

56 La superficie de Irlanda del Norte es de unos $14.139 \mathrm{~km}^{2}$. Con una población de 1.578.000 habitantes, representa menos del 3 por ciento del total del Reino Unido.
} 
se ajustaría cómodamente al caso de Escocia 57 y mucho menos al de Inglaterra 58 .

En resumen, parece más apropiado usar el término de nación para las cuatro que constituyen el Reino Unido. Sin embargo, algunas veces son llamadas regiones ${ }^{59}$, y, en realidad, en cierto sentido sí lo son. Simplemente, podemos afirmar que son los equivalentes funcionales de las regiones en el Reino Unido, ante la ausencia de otro tipo de regiones.

Si dejamos a un lado las cuatro naciones, el Reino Unido realmente carece de un nivel intermedio de gobierno regional. En verdad, podríamos decir que no sólo hay ausencia de gobierno regional, sino que también hay ausencia de regiones, dado que no hay una delimitación coherente de sus fronteras, de su tamaño o incluso del propio concepto de región.

Precisando más, quizás deberíamos decir que hay una ausencia de gobierno regional si nos movemos en el terreno constitucional. El concepto de región sí se va a poder encontrar en los escalones más bajos de la administración pública 60.

Por ejemplo, alguno de los departamentos gubernamentales de base funcional, como el Ministerio del Interior, el Ministerio del Medio Ambiente, Hacienda, el Ministerio de Comercio y el de Transportes, tienen organizaciones regionales para algunas de sus actividades. Se han usado "Regiones para la planificación económica" por los distintos gobiernos para formular su política regional de asistencia a las áreas más deprimidas, Las administraciones sanitarias son llamadas "consejos regionales" ${ }^{61}$, de

57 Escocia cubre aproximadamente un tercio de la superficie del Reino Unido, con más de $78.730 \mathrm{~km}^{2}$. Su población, unos 5.094 .000 de habitantes, es un 9 por ciento del total de la población del Reino Unido. Como se ha anotado más arriba, el término "regiones» es normalmente usado para designar los 9 entes locales de nivel más alto en que se divide Escocia (lo que apoya la postura aquí mantenida).

58 Inglaterra tiene una superficie de $130.345 \mathrm{~km}^{2}$ y una población de 47.536 .000 habitantes, que supone más de un 80 por ciento de la población total del Reino Unido.

59 La administración pública de radiodifusión, la BBC, diplomáticamente (o por indecisión) se refiere a Escocia, Gales e Irlanda del Norte como "regiones nacionales".

60 Ver, BRIAN HOGWOOD y MICHAEL KEATING (comp.), Regional Government in England, 1982: D. MARQUAND, «Regional Devolution», en J. JOWELL y D. OLIVER, (comp.), The Changing Constitution, $2^{\mathrm{a}}$ Edición, 1989.

61 N. del T.: «Regional boards». 
la misma forma que las recientemente privatizadas industrias del agua y de la electricidad funcionaban antes a través de administraciones regionales. Muchos de los llamados comités, comisiones y organizaciones nacionales, tales como, el Organismo para la Salud y la Seguridad 62 o la Comisión Forestal 63, operan tanto regionalmente como centralmente. La BBC tiene algunos centros regionales para la realización de programas, mientras que la principal cadena de televisión comercial (ITV o Canal 3) ha operado con una estructura regional desde su implantación en 1954.

Sin embargo, el número y las fronteras de las regiones no son comunes para todos estos propósitos. En realidad, escasamente coinciden para dos casos. El intento del Tesoro en 1964 de establecer para el gobierno central nueve "Regiones Estándar» en Inglaterra no duró mucho tiempo. Unos pocos años después, los miembros de una comisión de investigación descubrieron que los departamentos del gobierno central dividían Inglaterra según los diferentes propósitos en un número de regiones que iba de dos a catorce ${ }^{64}$.

La misma comisión observó que cualquier división de Inglaterra en regiones "tendría que ser hasta cierto punto artificiosa» 65 ante la ausencia de características diferenciadoras como las de Escocia y Gales. Algunas partes de Inglaterra, tales como el Noreste y el Suroeste, realmente tienen una clara identidad regional (que es lo mismo que decir que sus fronteras pueden ser fácilmente trazadas). Hay otras partes en las tierras medias, sur y este del país que cualquier división en regiones sería necesariamente artificiosa, dado que las identidades regionales son inexistentes o muy débiles ${ }^{66}$.

\section{CONCLUSIÓN}

La comisión de investigación a la que antes hicimos referencia fue una Comisión Real sobre la Constitución, establecida después de que

\footnotetext{
62 N. del T.: "The Health and Safety Executive».

${ }^{63}$ N. del T.: "The Forestry Commission».

64 Royal Commission on the Constitution 1969-1973, vol. 2, Memorandum of Dissent (Cmnd. 5460-1), para. 158.

65 Royal Commission on the Constitution 1969-1973 (Cmnd. 5460), para. 208.

66 Ver, CHRISTOPHER HARVIE, "English Regionalism: The Dog That Never Barked", en BERNARD CRICK (comp.) National Identities, 1992.
} 
los partidos nacionalistas en Escocia y Gales tuvieron ciertas victorias electorales en los años sesenta. Tuvo un amplio cometido, al habérsele pedido que «examinara las funciones actuales del legislativo y gobierno centrales en relación con los varios países, naciones y regiones del Reino Unido, y que considerara ...si son deseables cambios... en las actuales relaciones constitucionales y económicas».

Informó en 1973, pero el rasgo más sobresaliente del trabajo de los comisionados fue la diversidad de sus puntos de vista 67 . Estuvieron de acuerdo en rechazar la independencia para Escocia y Gales. También acordaron rechazar la solución federal para el Reino Unido. De hecho, el federalismo fue rechazado con ligeros argumentos sobre la base de que «el Reino Unido no es un lugar apropiado para el federalismo" y porque «hay muy poca demanda de federalismo en Escocia y Gales, y prácticamente ninguna en absoluto en Inglaterra».

Más allá de esas bastante débiles y discutidas conclusiones, los comisionados encontraron muy difícil el ponerse de acuerdo. Una mayoría estaba a favor de la descentralización legislativa para Escocia, otra mayoría lo estaba a favor de una especie de asamblea elegida para Gales, aunque había diferentes opiniones sobre las competencias que debía ostentar. Otra apoyaba la creación de ocho consejos regionales en Inglaterra, que tendrían sólo funciones deliberadoras y de consulta.

Un informe minoritario fuertemente discutido realizado por dos comisionados disidentes, proponía un esquema de un gobierno de nivel intermedio ${ }^{68}$. Como creían que las causas de insatisfacción con el gobierno eran comunes a todas las partes de Gran Bretaña, ellos sugirieron que las reclamaciones de Escocia y Gales de nacionalidad no legitimaban a la población de esos países para estar mejor gobernadas o para tener una mayor participación en sus propios asuntos que la gente de Lancashire o Yorkshire ${ }^{69}$.

Las propuestas relativas a las regiones fueron tranquilamente ignoradas. Unos años más tarde, un Gobierno laborista —después de varias

67 Royal Commission on the Constitution 1969-1973, (Cmnd. 5460). Ver, en general, HARRY CALVERT (comp.), Devolution, 1975; VERNON BOGDANOR, Devolution, 1979. Los comisionados se precavieron enormemente de hacer recomendaciones para Irlanda del Norte, en vista del turbulento estado de las cosas que allí había.

68 Royal Commission on the Constitution 1969-1973, vol.2, Memorandum of Dissent (Cmnd. 5460-1).

${ }^{69}$ Estos son condados del norte de Inglaterra muy populosos. 
derrotas en elecciones parciales - había perdido su mayoría absoluta en la Cámara de los Comunes, fue inducido a sacar adelante propuestas para la creación de asambleas directamente elegidas en Escocia y Gales, la Escocesa teniendo competencias legislativas y la Galesa sólo ejecutivas. Sin embargo, una enmienda promovida por un sector minoritario 70 que el Gobierno fue forzado a aceptar iba a resultar fatal. La Ley para Escocia de 1978 y la Ley para Gales del mismo año no llegaron a entrar en vigor ya que no recibieron el suficiente apoyo del electorado local en los referendums que se celebraron para satisfacer los términos de la enmienda mencionada 71 .

Desde 1979, todos los gobiernos han sido del partido conservador. Dado que su filosofía es "unionista» y tradicionalmente han defendido un gobierno fuerte, siempre han encontrado muy poco atractivas las ideas de crear nuevos niveles intermedios de gobierno o de mejorar el reconocimiento constitucional de las naciones.

Los progresos que se vayan haciendo en la Comunidad Europea podrán inspirar la creación de nuevos niveles intermedios de gobierno a largo plazo, pero a corto plazo no es probable que provoquen ningún cambio. La propia política regional de la Comunidad, tal como es, ha sido desarrollada a través de la participación de los Estados miembros y no ha necesitado nuevas estructuras políticas. El Tratado de Maastricht establece un nuevo Comité de las Regiones, que debe ser consultado en ciertas propuestas, aunque su papel sea sólo consultivo. Sin embargo, es el Consejo (y por tanto el ministro del gobierno central) el que designa los miembros del Comité. Al tiempo de escribir este trabajo, no se ha anunciado todavía cómo pretende el gobierno del Reino Unido cubrir su cuota de plazas en el Comité, pero lo que tenemos por cierto es que no va a crear nuevas instituciones políticas para tal propósito.

Sin embargo, las cuestiones relativas a la descentralización retornarán a la discusión política si cambia el partido en el gobierno. El tercer partido en la política británica, el Partido Liberal Democrático, tiene una larga tradición de simpatía por el federalismo. Lo que es más im-

\footnotetext{
$70 \mathrm{~N}$. del T.: Esta enmienda era una "backbench amendment», esto es, una enmienda presentada por algún diputado disidente de la corriente principal de su partido - normalmente el mayoritario - y que se sienta en los escaños del fondo —de ahí, su nombre-.

71 En Escocia, la mayoría de los que votaron lo hizo a favor, ya que un 32,9\% del electorado dijo "Sín" y un 30,8\% dijo "No". Pero no fue bastante para satisfacer los términos que preveía la Ley. En Gales sólo el 11,9 del electorado votó afirmativamente.
} 
portante, el Partido Laborista ha abandonado las posiciones estatalistas y centralistas que había ocupado con anterioridad. Se presentó a la última campaña de elecciones generales en 1992, habiendo suscrito un plan firme en pro de un Parlamento escocés, y con unos planes algo más vagos de Asambleas en Gales y en las regiones de Inglaterra que tuvieran tal voluntad.

Cuando estos temas realmente vuelvan a discutirse, habrá muchas cuestiones difíciles que habrán de ser resueltas. Como hemos podido demostrar, el Reino Unido es un Estado unitario, pero no de naturaleza simple. Una parte del Estado, físicamente separada, tiene el problema adicional de agudas divisiones entre sus comunidades. Hay otros factores concretos como las reclamaciones de nacionalidad, y una ausencia de regiones naturales, que son muy problemáticas, pero no exclusivas del Reino Unido. Otros Estados, incluida España, han afrontado estos temas con más urgencia y más seriamente que lo ha hecho el Reino Unido, de cuya experiencia podemos aprender una buena lección. 